\title{
On the Relationship between Problem-solving Trait and the Performance on C-test
}

\author{
Mina Ghodrati \\ Department of English Language Teaching, Torbat-e Heydarieh Branch, Islamic Azad University, Iran
}

Lida Bavandian

Department of Teaching English Language, Shahroud Science and Research Branch, Islamic Azad University, Iran

\author{
Mostafa Morady Moghaddam (Corresponding Author) \\ Young Researchers and Elite Club, Mashhad Branch, Islamic Azad University, Mashhad, Iran
}

Atena Attaran

Ferdowsi University of Mashhad, Iran

\begin{abstract}
Individuals attend language classrooms with miscellaneous personal attributes which are going to influence learners' test performance. Therefore, individual differences play an important role in sources of variance in test scores. This paper aims at investigating the effect of problem solving on the language ability obtained through C-tests. To this end, 70 EFL learners were randomly chosen and they were required to fill Parker's Problem-Solving Style Questionnaire (PSSQ). Simultaneously, they were given three C-tests to complete. The PSSQ measures four functions of problem solving: Sensing, Intuitive, Feeling, and Thinking. These four functions are the independent variables of this research. The Multiple Regression showed that there is a high positive correlation between $C$-test and intuitive (.844) and thinking $(.838)$ functions. The results also point out a large effect size $\left(R^{2}=.786\right)$ for correlations which in turn describes how much of the variance in dependent variable is accounted for by the four functions of problem solving. To link theory into practice, the pedagogical implications in the EFL context are discussed.
\end{abstract}

Index Terms - problem solving, multiple regression, personal attributes, PSSQ questionnaire, C-test

\section{INTRODUCTION}

An alternative form of cloze test, C-test has been widely used to investigate learners' proficiency level. As it is stated by Mousavi (1999, p. 78), in C-test, "the second half of every second word is deleted, leaving first and the last sentence of the passage intact." The term cloze comes from the Gestalt psychology in which it is believed that individuals are able to fill in the gaps in incomplete patterns (Bachman, 1985; Taylor, 1956). Therefore, C-test requires learners to establish a relationship between linguistic elements and contextual cues. As it is mentioned by Mousavi (1999, p. 40) and advocated by Oller (1979), "The cloze technique ... approaches comprehension of meaning and pattern relationships directly through the reader." C-test originates from a dominant paradigm to language testing which is the integrative approach (Farhady et al., 2009). This view of testing advocates the use of language not in discrete-point form but in the context of larger sentences. C-test, as an alternative to cloze test, came to the vogue after Klein-Braley and Raatz (1981). It has been advocated that C-test provides several advantages over cloze test (Raatz \& Klein-Braley, 1983) one of which is the ability of C-test to measure specific linguistic elements in a text (Weir, 1993). Moreover, Farhady $(1980,1983,1996)$ criticized cloze test on the grounds that it distorts the assumption of item independence which is an index of reliability and validity in classical test theory. C-test has been theoretically justifiable since it "is based upon the same theory of closure or reduced redundancy as the cloze test" (Alderson, 2000, p. 225). Another advantage of cloze test is related to marking process. As it is postulated by Weir (1990), since testees are to restore the words, test takers have littler difficulties evaluating learners' proficiency.

When words such as comprehension and organizing are highlighted, the role of thinking becomes much more outstanding. One of the skills which can impose control and discipline over thinking is problem solving skill. Problem solving is a cognitive process that imposes control over memory and leads memory toward appropriate selection of activities. These activities are utilized to solve the challenges individuals encounter in their tasks (Sutherland, 2002). Steckroth et al. (1980) defined problem solving as "processes through which individuals organize information from the environment and evaluate it" (p. 77).

The first models of problem-solving styles came from the theory of psychological functions which was developed by Carl Jung (1923). This theory has been further developed by Mitroff and Kilmann (1978) and Zmud (1979). Jung's model consists of four psychological functions as thinking, feeling, sensation, and intuition. Feeling and thinking are placed in opposite sides on a continuum. As it is advocated by researchers, one of the functions is more likely to be 
stronger in an individuals' problem-solving style (Jung, 1923). Steckroth et al. (1980, pp. 78-79) determined the scope of each of these functions as below:

- Dominant Feeling Style. These managers are aware of other people's feelings, tend to be sympathetic, and dislike telling people unpleasant things. They tend to make decisions that are likely to result in approval from others, such as one's peers or subordinates, and avoid decisions that will likely result in disagreements. The establishment of friendly relations may even supersede and possibly interfere with a concern for achievement, effectiveness, and sound decisions. A feeling type, therefore, is likely to emphasize affective and personal processes in reaching a decision.

- Dominant Thinking Style. These managers are constantly trying to make decisions through intellectual processes. These intellectual processes are based upon external data and/or generally accepted ideas and values. Thinking types often try to fit problems and their solutions into standardized formulas. There is considerable similarity between the thinking style, major elements in the scientific method, and most modern theories of decision processes that stress rationality, such as mathematical decision theory and game theory.

- Dominant Sensation Style. Sensation type managers dislike new problems unless there are standardized ways to solve them, and prefer routine to non-routine work. In essence, these managers usually dislike coping with unstructured problems that contain considerable environmental uncertainty. In popular terms, sensation types are detail people. They gather data (that are highly specific and factual) from their environment through the use of the five senses.

- Dominant Intuition Style. These managers like to solve new problems, are impatient with routine details, and dislike taking time for precision. Whereas the sensation managers tend to perceive the environment in terms of detailed facts and specific events, intuitive managers tend to perceive the whole environment or the totality of the environment.

Throughout the history of SLA, some methods and approaches toward language teaching have targeted the writing skill to show its nature and its intricacies. Whole Language proponents, for instance, advocated that "writing is not primarily as a means of demonstrating knowledge to a teacher, but a way of discovering for oneself what one thinks" (Rigg, 1991, p. 522). Maybe it is the process of thinking itself which render the task so cumbersome. Moreover, as it is mentioned by Cottrell (2005), it is difficult for many individuals to manage their thoughts in a logical and consistent way. Maybe the key to success in improving writing skill is laid outside the realm of linguistic elements. For solving the mystery of writing skill, other areas such as the ability to reason and logic may prove to be useful - two major aspects of critical thinking.

When words such as discovering and introspection are highlighted in a particular activity, the role of thinking becomes much more obvious. Some researchers have stated that thinking and writing skill go hand in hand and are inseparable (Brown, 2001); therefore, the better one thinks, the better that person is going to deal with writing. Unfortunately, EFL curriculum is alienating itself from such important aspect of education — critical thinking. Moon (2008) believed that, "although thinking must surely be at the heart of education, it is not often explicitly taken into consideration in pedagogy" (p. vii). As learners grow up in their academic life, some crucial elements of education become much more outstanding though unknown to most learners and, disappointingly, to many educators. In order to think well, one should impose control and discipline on his/her thinking. This imposition is called critical thinking.

The importance of critical thinking has been addressed variously through educational life. Taylor and Mackenny (2008) stated that "critical thinking is a natural outgrowth of normal educational efforts" (p. 131). In Toward a postmethod pedagogy, Kumaravadivelu (2001) proposed the idea of "liberatory autonomy" in which the learners are empowered with critical thinking skills (p. 547). As the review of literature reveals, critical thinking is an underlying element of any educational effort and surely one cannot separate writing from critical thinking. According to Zamel (1982, p. 197), "writing is the record of an idea developing" in which individuals should manage their thoughts to come up with a consistent and coherent writing. Critical thinking is a subject of considerable current interest, both in terms of theory and pedagogy and most researchers have advocated the integration of critical thinking into other areas of foreign language learning (Bailin, Case, Coombs, \& Daniels, 1999).

This study tires to investigate the way these styles are going to alter performance on C-test. Beside the aforementioned goal, this study embraces the following questions:

1. Is there any significant relationship between each of four functions of problem solving and C-test?

2. Which of the problem solving functions has the most influence on the variation in learners' C-test scores?

3. Is there any significant relationship among four problem-solving functions?

\section{METHODOLOGY}

\section{A. Participants}

In order to measure the effect of problem solving on C-test, 70 EFL learners were randomly chosen from different institutes in Mashhad, Iran. Gender was equally distributed among learners with 35 persons in each gender. They were aged between 18 and 30. All of the learners spoke Persian as their main language in home and they were able to speak Persian as the national language too. Learners' proficiency level was mainly advanced. The criterion to figure out their proficiency level was the placement test of the institute as well as the terms they had passed.

\section{B. Instruments}


$C$-test: To investigate learners' proficiency score, three passages in which the second half of every other word is deleted were given to students. The three texts have been adopted from Mousavi (1999, p. 80). The texts are from different fields and enjoy different levels of difficulty. Totally, there are 80 mutilated words in three passages and the length of each passage is nearly the same. In order to make the statistical process more manageable, the score of each testee is divided to 4, which provides a score of 20 for each learner. The passages are mentioned in Appendix 1.

Problem Solving Style Questionnaire: In this study, Parker Problem Solving Style Questionnaire (PSSQ) is used which includes 20 Likert scale. The questionnaire measures four concepts of problem solving as Sensing, Intuitive, Feeling, and Thinking. Therefore, each concept embraces five questions (Appendix 2).

Procedure: Learners were required to answer three C-tests and after that they were given the PSSQ to put their answers on a Likert scale. Then, the papers were gathered and they were investigated by two independent raters. When the data were investigated, the Multiple Regression was used to study the effect of each problem solving concept on the performance of C-tests.

\section{RESULTS}

Since the goal of this article is to investigate the effect of independent variables, which are the four concepts of problem solving mentioned earlier, on the dependent variable, which is C-test, Multiple Regression is the suitable path. In using this model, the shape of the distribution of dependent variable is of key importance. The distribution of dependent variable defines the nature of relationships between dependent and independent variable to find whether it is a linear or a nonlinear one. If the distribution is normal, it is possible to show the relation between dependent and independent variable through a linear or a multiple regression. Therefore, before choosing the model, the dependent variable should be investigated. To this aim, a histogram is used which is showed in Figure 1. According to this figure, the distribution of Skewness is to left and the statistics reveal an amount of -.930 for Skewness which is pointed out in Table I. Since this amount is less than one, it is possible to consider normal distribution for the dependent variable.

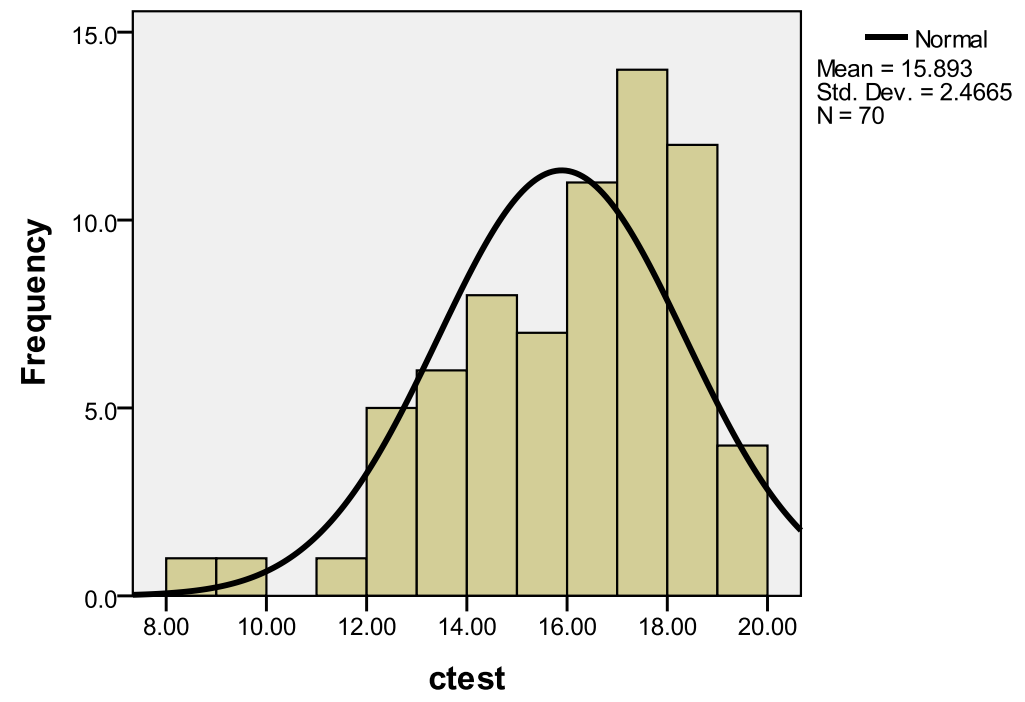

Figure 1. The Distribution of Dependent Variable

To figure out the nature of relationships between dependent and independent variables, the data was put into SPSS. Table I shows the descriptive statistics of the results:

TABLE I

DESCRIPTIVE STATISTICS

\begin{tabular}{|l|l|l|l|l|l|l|l|}
\hline & $\mathrm{N}$ & Mean & Variance & Skewness & \multicolumn{3}{l|}{ Kurtosis } \\
\cline { 2 - 7 } & Statistic & Statistic & Statistic & Statistic & Std. Error & Statistic & Std. Error \\
\hline C-test & 70 & 15.8930 & 6.084 & .930 & .287 & .741 & .566 \\
Valid N (listwise) & 70 & & & & & \\
\hline
\end{tabular}

After the preliminary investigations, the data was put into SPSS for estimating the nature of relationships among variables. Figure 2 shows the correlations between dependent and independent variables as well as the nature of correlations among the independent variables ( $\mathrm{S}=$ Sensing; I= Intuitive; $\mathrm{F}=$ Feeling; $\mathrm{T}=$ Thinking) 


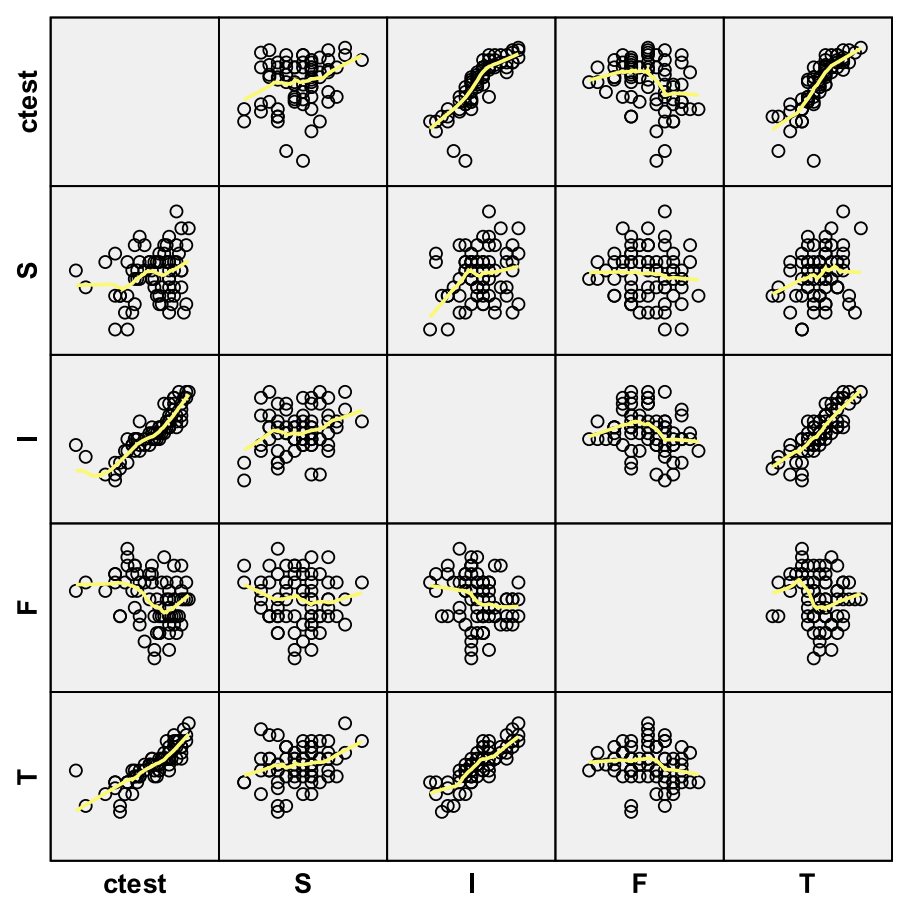

Figure 2. The Relationship between Dependent and Independent Variables

Figure 2 shows that there is a high positive correlation between the dependent variable and independent variables of thinking and intuitive. Furthermore, the two independent variables of intuitive and thinking have a high correlation with each other.

TABLE II

PEARSON CORRELATIONS AMONG THE VARIABLES AND THEIR SIGNIFICANCES

\begin{tabular}{|ll|l|l|l|l|l|}
\hline & & C-test & S & I & F & T \\
\hline Pearson Correlation & C-test & 1.000 & .247 & .844 & -.307 & .838 \\
& S & .247 & 1.000 & .246 & -.098 & .265 \\
& $\mathrm{I}$ & .844 & .246 & 1.000 & -.235 & .840 \\
& $\mathrm{~F}$ & -.307 & -.098 & -.235 & 1.000 & -.167 \\
& $\mathrm{~T}$ & .838 & .265 & .840 & -.167 & 1.000 \\
\hline Sig. (1-tailed) & C-test &. & .020 & .000 & .005 & .000 \\
& $\mathrm{~S}$ & .020 &. & .020 & .209 & .013 \\
& $\mathrm{I}$ & .000 & .020 &. & .025 & .000 \\
& $\mathrm{~F}$ & .005 & .209 & .025 & .083 & .083 \\
& $\mathrm{~T}$ & .000 & .013 & .000 & .083 &. \\
\hline
\end{tabular}

Pearson correlation has a coefficient between 1 and zero. As Table II reveals, the correlation between the dependent variable of $\mathrm{C}$-test and the independent variable of intuitive is 0.844 and the correlation of $\mathrm{C}$-test with the independent variable of thinking is 0.838 which are high positive correlations. This is to say that there is a high positive correlation between dependent variable and intuitive and thinking concepts of problem solving. Table II points out that there is significant correlation between dependent variable and independent variables. This is in part because of the large number of participants in the study. The results show that there is a weak correlation between the dependent variable and two independent variables, namely, feeling and sensing.

TABLE III

MODEL SUMMARY

\begin{tabular}{|l|l|l|l|l|}
\hline Model & $\mathrm{R}$ & R Square & Adjusted R Square & Std. Error of the Estimate \\
\hline 1 & .886 & .786 & .772 & 1.17679 \\
\hline
\end{tabular}

In the end, the most important information that can be obtained from Table III is the amount of R Square which equals .786. This figure shows that 78.6 percent of the changes in the dependent variable is for the sake of independent variables not by chance alone. To verify the changes in the dependent variable, two conditions should be met:

1. The variance should be fixed.

2. Errors should have a normal distribution 
For investigating whether the variance is stable or not, the diagram of dependent variable with regarding the errors has been showed in Figure 3. If the diagram is like a funnel, the variance is not stable and fixed. Figure 3 shows that the variance is fixed.

\section{Scatterplot}

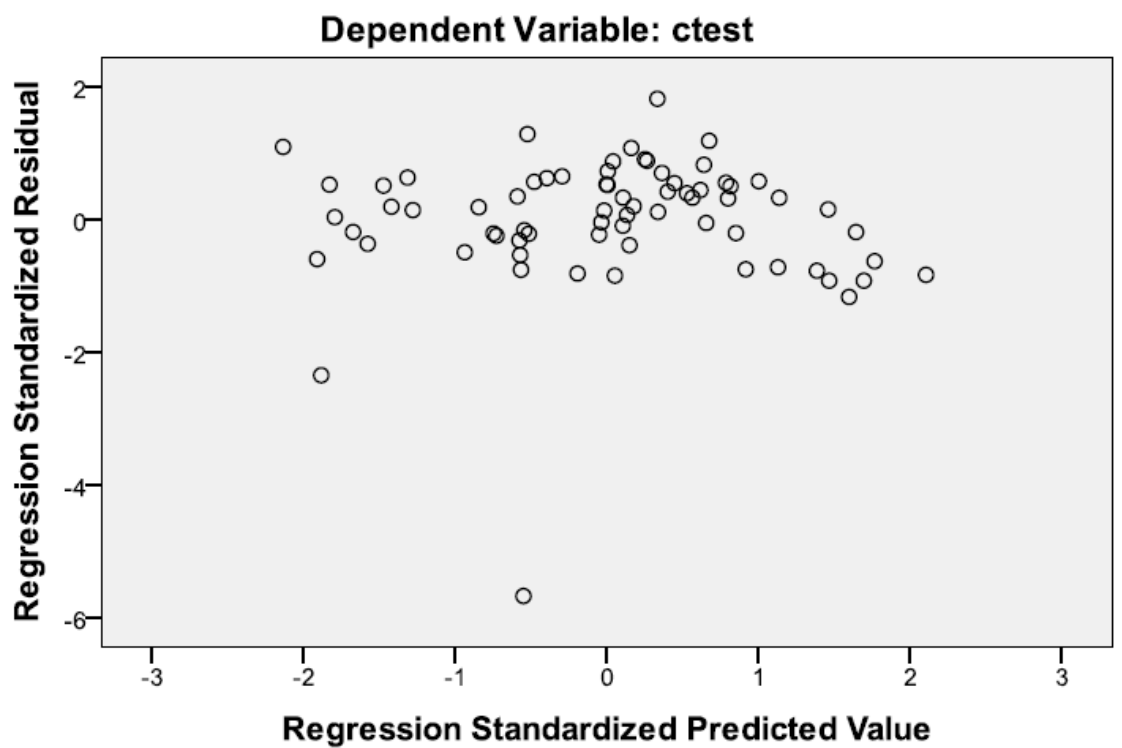

Figure 3. The diagram of dependent variable with regarding the errors

For investigating the degree of normal distribution of errors, Q-Q diagram should be used. If the distribution of dots is concentrated around the line, the data are distributed normally. As it can be seen in Figure 4, errors have a normal distribution.

\section{Normal P-P Plot of Regression Standardized Residual}

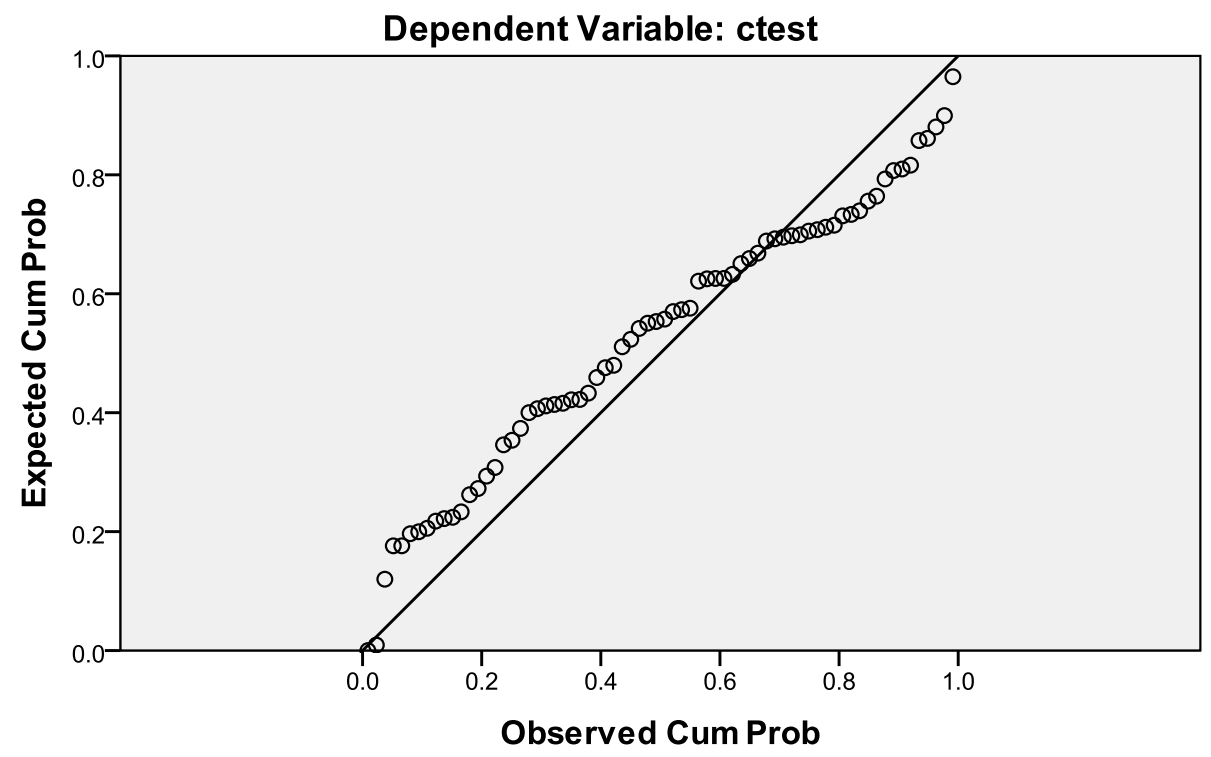

Figure 4. The degree of normal distribution of errors

\section{DISCUSSION AND IMPLICATIONS}

The first question of this study was to investigate whether there is any significant relationship between each of the four categories of problem solving and C-test. The results showed that there is a high positive correlation between Ctest and two concepts of problem solving which were thinking and intuitive. The second question of this article was to understand which of the problem solving categories has the most influence on the variation in learners' C-test scores. Intuitive learners were performed better on C-tests and this shows that being intuitive has the most influence on the 
variance of C-test. The third problem of this study deals with finding whether there is any significant relationship among the four independent variables. The results showed that there is a high correlation between thinking and intuitive variables.

As for the implications of this study, it can be mentioned that teachers in EFL classes can use thinking and intuitive activities to increase learners' proficiency. The importance of this study is fourfold. First, it is useful for the EFL learners in that they will be familiar with the dominant problem solving functions and they can increase their problem solving abilities to enhance their performance on language proficiency tests. Furthermore, the findings of this study may be a fruitful source for EFL learners in order to be acquainted with the effects of problem solving functions of language performance. When learning L2, most students resort to linguistic strategies in order to come up with different drawbacks in performing a task. However, some problems are in relation with psychological processes. Acquainting and teaching learners some problem solving techniques can solve their problems performing tasks in language classrooms. The findings can help EFL learners to overcome the difficulty of using appropriate paths in various situations. Second, teachers as the conductors of the class can use the findings in order to instruct learners. This study also helps teachers to find out why some students have problems learning and applying the language appropriately. Third, this study may be of interest for material developers. Learners interact most of their time with their books. Textbooks are also a road map for most teachers and students. Material developers can use the findings of this study to develop and provide beneficial exercises in order to increase learners' problem solving abilities. Learning problem solving techniques may increase the quality of leaning and performance among individuals.

Fourth, researchers can use the findings of this study to compare and contrast different learners' proficiency level based on a model of problem solving. It is also of great help to those who want to investigate individual differences in language classes. Moreover, it is possible for the researchers to study whether individuals in different situations and different contexts reveal the same patterns of problem solving functions mentioned in this paper.

\section{Appendix A. Cloze Tests Used in the Study}

\section{C-Test 1}

Controlling the pollution is another crucial objective. Without fo-----------, man c-----------, live f----------- about fi---------- weeks; with---------- water ab---------- five da----------. Without a----------, he c---------- only li--------- five min-----------, so pu----------- air i----------- a mu-----------. Here t----------- wrongdoer i----------- the autom-----------. Where th--------- is a concern of autom---------, as i--------- our b---------- cities, a---------- pollution i-------severe. I----------- is impo----------- to s----------- that o----------- cars a----------- equipped wi----------- pollution-control dev----------. Such devices effectively reduce the harmful gases emitted from the engine.

\section{C-Test 2}

There are usually five men in the crew of a fire engine. One o---------- them dri----------- the eng----------. The lea------ engine. T----------- the dri---------. The ot--------- firemen s---------- will kn---------- how t---------- fight diff---------- sorts o---------- fires. S---------, when t----------

ApPEndix B. Problem-SOlving Style QuestionnAire (PSSQ) 


\section{Statement}

1. Most people think that I am objective and logical

2. Most people would say that I am emotional and rather motivating

3. Most people believe that I know the details of my job and do it very accurately

4. Most people agree that I am a complex and intellectual person

5. I tend to focus on immediate problems and let others worry about the distant future

6. I try to please others and need occasional praise myself

7. When I face a problem, I try to analyze all the facts and put them in systematic order

8. I'm more interested in long-range implications and am often bored with minor here and now details

9. I'm usually more people oriented than task oriented

10. Before I put energy into a project, I want to know what's in it for me

11. I normally solve problems quickly without wasting a lot of time on details

12. When I have a job to do, I do it, even if others' feelings might get hurt in the process

13. I get bored with routine and prefer to deal with new and complicated challenges

14. I'm a pretty good judge as to how others feel about problems

15. I don't let problems upset me, no matter how difficult they are

16. I like to do things that I do well, but I'm not comfortable trying to learn new skills

17. I prefer harmony in a work group —otherwise efficiency suffers

18. I really enjoy solving new problems

19. I am a quick learner, but I don't like theoretical, futuristic concepts

20. When necessary, I have no trouble making tough, hard-nosed decisions

\begin{tabular}{|c|c|c|c|c|}
\hline $\begin{array}{l}\text { Strongly } \\
\text { agree }\end{array}$ & $\begin{array}{l}\text { Slightly } \\
\text { agree }\end{array}$ & $\begin{array}{l}\text { Not } \\
\text { sure }\end{array}$ & $\begin{array}{l}\text { Slightly } \\
\text { disagree }\end{array}$ & $\begin{array}{l}\text { Strongly } \\
\text { disagree }\end{array}$ \\
\hline 5 & 4 & 3 & 2 & 1 \\
\hline 5 & 4 & 3 & 2 & 1 \\
\hline 5 & 4 & 3 & 2 & 1 \\
\hline 5 & 4 & 3 & 2 & 1 \\
\hline 5 & 4 & 3 & 2 & 1 \\
\hline 5 & 4 & 3 & 2 & 1 \\
\hline 5 & 4 & 3 & 2 & 1 \\
\hline 5 & 4 & 3 & 2 & 1 \\
\hline 5 & 4 & 3 & 2 & 1 \\
\hline 5 & 4 & 3 & 2 & 1 \\
\hline 5 & 4 & 3 & 2 & 1 \\
\hline 5 & 4 & 3 & 2 & 1 \\
\hline 5 & 4 & 3 & 2 & 1 \\
\hline 5 & 4 & 3 & 2 & 1 \\
\hline 5 & 4 & 3 & 2 & 1 \\
\hline 5 & 4 & 3 & 2 & 1 \\
\hline 5 & 4 & 3 & 2 & 1 \\
\hline 5 & 4 & 3 & 2 & 1 \\
\hline 5 & 4 & 3 & 2 & 1 \\
\hline 5 & 4 & 3 & 2 & 1 \\
\hline
\end{tabular}

\section{REFERENCES}

[1] Alderson, J. C. (2000). Assessing reading. Cambridge: Cambridge University Press.

[2] Bachman, L. F. (1985). Performance on cloze tests with fixed-ratio and rational deletion. TESOL Quarterly, 19, 535-556.

[3] Bailin, S., Case, R., Coombs, J., \& Daniels, L. (1999). Common misconceptions of critical thinking. Journal of Curriculum Studies, 31(3), 269-283.

[4] Beichner, R. J. (2002, June 26). GOAL oriented problem solving. Retrieved September 30, 2008, from http://www.ncsu.edu/ncsu/pams/physics/Physics_Ed/Authors/Beichner.html

[5] Brown, H. D. (2001). Teaching by principles: An interactive approach to language pedagogy. Englewood Cliffs, NJ: Prentice Hall Regents. (2nd ed.). White Plains, NY: Longman.

[6] Cottrell, S. (2005). Critical thinking skills: Developing effective analysis and argument. Basingstoke, Hampshire: Palgrave Macmillan Ltd.

[7] Raatz, U., \& Klein-Braley, C. (1983). Ein neuer Ansatz zur Messung der Sprachleistung. Der C-test: Theorie und Praxis. In R. Horn, K. Ingencamp, \& R. Jager (Eds.), Tests und Trends, Jahrbuch der Padagogischen Diaanostik (pp. 107-138). Weinheim: Beltz.

[8] Farhady, H. (1980). Justification, development, and validation of a functional language proficiency test. Unpublished PhD dissertation, UCLA.

[9] Farhady, H. (1983). New directions for ESL proficiency testing. In J. W. Oller (ed.), Issues in language testing research (pp. 253-268). Rowley, Mass.: Newbury House.

[10] Farhady, H. (1996). Varieties of cloze procedure as a teaching and a testing device. Roshd Foreign Language Teaching Journal, 12(44), 217-229.

[11] Farhady, H., Ja 'farpur, A., \& Birjandi, B. (1387/2009). Testing language skills: From theory to practice. Tehran: SAMT Publications.

[12] Jung, C. (1923). Psychological Types. London: Rutledge and Kegan Paul, Ltd.

[13] Kumaravadivelu, B. (2001). Toward a postmethod pedagogy. TESOL Quarterly, 35, 537-560.

[14] Mitroff, I., \& Kilmann, R. (1978). On integrating behavioral and philosophical systems: Towards a unified theory of problem solving. Annual Series in Sociology, 1, 207-236. (1978).

[15] Moon, J. (2008). Critical thinking: An exploration of theory and practice. NY: Routledge.

[16] Mousavi, S. A. (1999). A dictionary of language testing ( $2^{\text {nd }}$ ed.). Tehran: Rahnama Publications.

[17] Oller, J. W. (1979). Language tests at school: A pragmatic approach. Landon: Longman.

[18] Pressley, M., \& McCormick, C. (1995). Cognition, teaching and assessment. New York: Harper Collins College Publishers.

[19] Rigg, P. (1991). Whole Language in TESOL. TESOL Quarterly, 25(3), 521-542.

[20] Taylor, G. R., \& Mackenny, L. (2008). Improving human learning in the classroom: Theories and teaching practices. NY: Rowman \& Littlefield Education.

[21] Taylor, W. L. (1956). Recent developments in the use of cloze procedure. Journalism Quarterly, 30, 414-433. 
[22] Steckroth, R. L., Slocum, J. W., \& Sims, H. P. (1980). Organizational roles, cognitive roles and problem-solving styles. Journal of Experiential Learning and Simulation, 2, 77-87.

[23] Sutherland, L. (2002). Developing problem solving expertise: The impact of instruction in a question analysis strategy. Learning and Instruction, 12, 155-187.

[24] Weir, C. (1990). Communicative language testing. Hemel Hempstead: Prentice Hall International Ltd.

[25] Weir, C. (1993). Understanding and developing language tests. NJ: Prentice Hall Inc.

[26] Zamel, V. (1982). Writing: The process of discovering meaning. TESOL Quarterly, 16(2), 195-209.

[27] Zmud, R. (1979). Perceptions of cognitive style: Acquisition, exhibition, and implications for information system design. Journal of Management, 5(1): 7-20.

Mina Ghodrati got her MA in TEFL at department of English language teaching, Torbat-e Heydarieh Branch, Islamic Azad University, Torbat-e Heydarieh, Iran. She is interested in teaching methodology, psycholinguistics, and e-learning.

Lida Bavandian is an MA student at Department of Teaching English Language, Shahroud Science and Research Branch, Islamic Azad University, Shahroud, Iran. She is interested in discourse analysis pragmatics.

Mostafa Morady Moghaddam is a third-year PhD candidate of TEFL at University of Tabriz and a member of Young Researchers and Elite Club, Mashhad Branch, Islamic Azad University, Mashhad, Iran.

Atena Attaran has got her MA in TEFL at Ferdowsi University of Mashhad. She is interested in pragmatics and discourse analysis. 